\title{
Lessons of Mitigation from a Low Frequency Debris Flow Event
}

\author{
Yongbo Tie ${ }^{1}$ Jintao Jiang ${ }^{1,2,3}$ \\ 1 Chengdu Center of China Geological Survey, Chengdu 610081, China \\ 2. China University of Geosciences Beijing, Beijing 100083, China \\ 3. Chinese Academy of Geological Sciences, Beijing 100037, China
}

\section{一次典型低频泥石流灾害过程及防灾减灾思考}

\author{
铁永波 ${ }^{1}$ 江金涛 ${ }^{1,2,3}$ \\ 1. 中国地质调查局成都地质调查中心, 四川成都 610081 , 中国 \\ 2. 中国地质大学, 北京, 100083, 中国 \\ 3. 中国地质科学研究院, 北京, 100037, 中国
}

\begin{abstract}
Tianbazigou locate at Daguan County in Yunnan province, which occurred a disastrous debris flow in 1997. Based on the field survey, this paper take this debris flow event as an example proposed these common problems which exist in low frequency debris flow research, and discussed the mainly research contents in the future for low frequency debris flow. This research is useful for low frequency debris flow edentify and mitigation.
\end{abstract}

Keywords:Low frequency debris flow; causes and mechanism; risk identifying; mitigation

\section{摘要}

论文以 1997 年云南省大关县田坝子沟泥石流 为例, 通过分析该次泥石流的成因机制, 引出 目前对低频泥石流认识中存在的一些共性问 题, 并对今后在低频泥石流研究中的重点内容 进行了阐述, 可为低频泥石流的危险性评价及 防灾减灾提供参考。
关键字: 低频泥石流; 成因机制; 风险识别; 防灾减灾

\section{1. 引言}

西南山区是我国泥石流的高发区, 同时也 分布有数量较多的低频泥石流。除了与中、高 频泥石流在暴发周期上存在差异外, 低频泥石 流造成的灾害往往也极为严重 ${ }^{[1,2]}$, 并产生不 良的社会影响 ${ }^{[3]}$ 。统计结果表明, 在以往泥石 流成灾历史上, 一次性造成重大灾害的往往都 是低频泥石流, 如 2010 年 “8.7” 舟曲泥石流 造成的重大灾害是目前我国泥石流灾害史上 最为严重的一次 ${ }^{[4]}$ 。一方面, 是受低频泥石流 所在地区地质构造及岩土体特征的影响, 汇集 一定规模的松散土体需要较长的时间, 以至于 历史上泥石流活动的许多痕迹被植被所掩盖, 容易让人忽略青山绿水间隐藏的潜在风险。另 一方面, 沟道内长时间堆积的小颗粒松散土体 在沟道径流的冲刷作用下被带走, 而在表层形 成一层粗颗粒的覆盖层, 并对底部的土体起到 保护作用, 只有在暴雨或特大暴雨诱发的洪水 条件下时, 这些大粗颗粒土体才容易被启动, 进而使得深层土体也随之起动形成泥石流 ${ }^{[5-7]}$ 。 
1997 年 5 月 6 日 22 时 30 分左右, 田坝 子沟暴发泥石流,造成 39 人死亡、 85 人受伤、 627 间房屋毁坏、直接经济损失 5000 万元以 上的重大灾害。据调查, 泥石流携带到沟口的 漂石最大重达 10 吨, 在沟口建筑和树干上留 下的泥痕高约 $12 \mathrm{~m}^{[8]}$ 。沟口右岸的当地派出所、 数十户民房、黄葛中学迎泥石流面第一层楼及 213 国道桥梁全部被毁, 其破坏性极大。19 年 过去了, 对于位于深切河谷区的这类泥石流沟, 侵蚀基准面的持续下降导致的主沟纵比降增 大, 流域内松散土体的稳定性降低, 经过多年 后的松散土体汇集规模也会逐渐增大。那么, 田坝子沟是具备发生下一次大规模泥石流的 可能性? 其潜在风险有多高? 基于这些疑问, 论文重点针对 1997 年田坝子沟泥石流的形成 过程机制及成因进行研究, 希望通过对典型泥 石流事件形成过程剖析, 可为地方政府部门认 识该泥石流的特征并开展相应的防灾减灾对 策提供科学依据。

\section{2. 田坝子沟泥石流流域特征}

田坝子沟位于云南省大关县中部, 位于县 城北面, 距县城约 $15 \mathrm{~km}$, 行政区划上属于大 关县悦乐镇。田坝子沟所处区域为川滇经向构 造带北段, 扬子准地台边缘, 新构造运动迹象 十分明显, 近代地震活动强烈, 出露基岩主要 为中变质砂岩和灰岩。区内以深切河谷地貌为 主, 大关河河谷深达几十米至百米以上, 坡度 多为 40 度以上。区域气候为北亚热带气候, 四季分明不是太显著。但由于地形复杂, 海拨 高低悬殊大, 立体气候特征尤其明显。全年平 均气温 $15^{\circ} \mathrm{C}$, 最高 $40.3^{\circ} \mathrm{C}$, 最低零下 $6.4^{\circ} \mathrm{C}$ 。 年平均日照时数 1014.2 小时, 日照率 $23 \%$ 。 年平均降水量 992.9 毫米。

田坝子沟泥石流流域面积 $13 \mathrm{~km}^{2}$, 主沟长 $4 \mathrm{~km}$, 流域最高海拔 $2051 \mathrm{~m}$, 沟口海拔 $670 \mathrm{~m}$, 主沟纵比降 345\%。流域整体呈扇状, 上宽下 窄的特征较为显著, 有利于沟道径流的快速汇 集, 进而对沟道内的松散堆积体产生侵蚀和冲 刷形成泥石流, 这也是西南山区低频泥石流的 典型流域形态特征之一。泥石流形成区位于海 拔 955m 2051m 之间, 是泥石流水动力条件汇 集和物源的主要形成区, 泥石流物源主要来自 中上游地区覆盖在基岩表层的第四纪残坡积
物, 尤以堆积在中游段沟道右岸的松散堆积体 为主。流通区位于主沟海拔 $710 \mathrm{~m} \sim 955 \mathrm{~m}$ 之间 的区域, 此段主沟宽 5 20m 不等, 沟道两侧 及沟底多为基岩出露, 沟道内松散堆积物较少, 在泥石流的形成过程中提供的物源量也极少, 对泥石流的规模变化的影响不大。泥石流堆积 区位于海拔 $670 \mathrm{~m} \sim 710 \mathrm{~m}$ 之间, 此处为老泥石 流堆积扇在后期沟道径流的下切作用后形成 的新沟道, 沟道宽 10 25m。老堆积扇主要位 于沟道左岸, 在横剖面形态上呈现阶梯状, 从 外观上能看出至少有两次大规模的堆积过程。 最顶上一层为最老的泥石流堆积物, 最近一次 泥石流堆积过程发生在 1997 年, 经过多年的 侵蚀, 在堆积扇右侧靠被切出的新沟道平均宽 度约 $13 \mathrm{~m}$, 深 3 $8 \mathrm{~m}$ 。在沟口开阔地, 泥石流 堆积扇沟道两侧的相对较高区域, 分布有黄暮 中学、烟叶站及当地民房, 老 213 国道亦横穿 泥石流堆积区（图 1)。

通过对沟口居民的访问得知, 1997 年是 当地居民记忆中的第一次大规模泥石流。对于 田坝子沟此前是否有发生过大规模泥石流, 当 地人都不太清楚, 也没能从相关的历史资料中 查找到相应的记录。从黄暮沟沟口的地貌特征 分析, 沟道的右岸高约 $20 \mathrm{~m}$ 的老堆积扇体不是 1997 年泥石流形成的, 表明此前这里也曾有 过更大规模的泥石流沉积过程, 并形成了现在 田坝子村所在的地形地貌。根据当地 72 岁老 人的回忆, 他也未曾听他们的祖辈提及过这里 曾发生过泥石流, 由此判断, 田坝子沟在 1997 年以前的 100 年内未发生过大规模泥石流。

\section{3. 田坝子沟泥石流成因分析}

\section{1 短时强降雨}

前期的研究表明, 短时强降雨是诱发低频 泥石流的主要降雨类型, 并与小时降雨量之间 具有较显著的相关性 ${ }^{[9]}$ 。通过对田坝子沟 1997 年诱发泥石流的降雨资料分析发现, 该次泥石 流过程也是由短时强降雨诱发。根据离黄葛沟 直线距离 $15 \mathrm{~km}$ 的大关气象站当日的观测数据 显示, 5 月 6 日 22: 00 22: 52 时, $66.4 \mathrm{~mm}$ 的降雨量集中在不到一小时内完成, 瞬间雨强 度可达 $3 \mathrm{~mm} / \mathrm{min}$ (图 2)。

将 22: $00 \sim 23: 00$ 时的降雨数据进一步 
Risk Analysis and Crisis Response in Big Data Era (RAC-16)

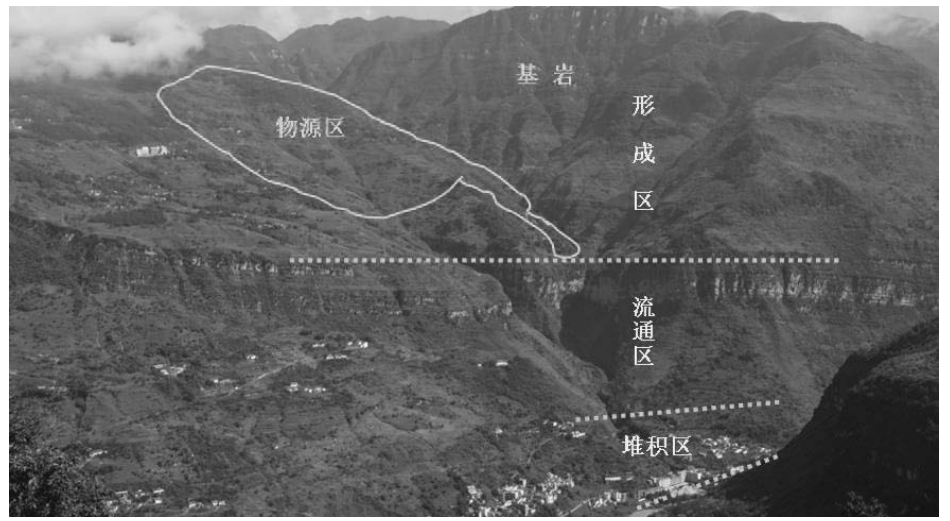

图 1. 田坝子沟泥石流沟流域特征

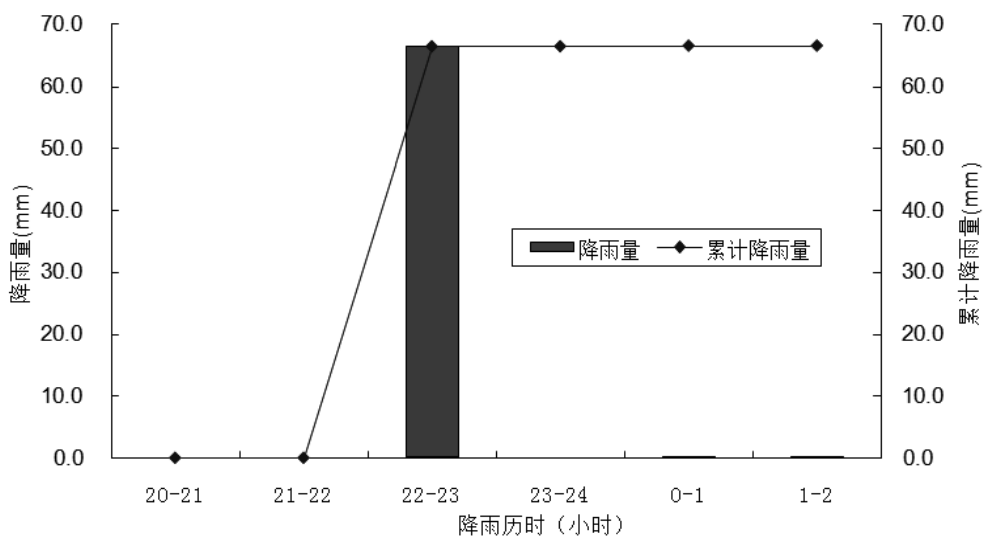

图 2, 田坝子沟泥石流发生时的降雨分布特征

分析发现, 该次降雨过程的峰值降雨量主要集 中在 22: 00 22: 05 之间, 5 分钟降雨量达 到 $17.6 \mathrm{~mm}$, 并在随后的 15 分钟内又完成了 $31.6 \mathrm{~mm}$ 的降雨量 (图 3)。由此可以看出, 该 次降雨量极为集中且强度极大, 田坝子沟泥石 流也就是在短短 20 分钟内被激发。

\section{2 中游右岸丰富物源}

根据现场的调查分析发现，1997 年泥石 流的物源, 主要由两个部分组成。第一部分来 自于流域上游（穆家寨以上）区域, 这一区域 沟道两侧多为基岩出露, 且两侧山坡坡度较陡, 基岩风化侵蚀后形成的崩坡积物多在沟道内 堆积。据当地老乡的访问结果, 在泥石流发生 前, 沟道内的松散堆积物厚度约为 $2 \mathrm{~m}$ 左右。
穆家寨以上区域的这部分松散固体物质在上 游沟道径流的冲刷作用下产生启动, 并形成高 含沙洪水或准泥石流流体冲出, 成为低频泥石 流物源启动中的启动型补给物源, 为泥石流的 形成提供了重要的前提。第二部分物源主要分 布在流域中游的沟道右岸, 为第四纪残坡积物, 堆积体长约 $2000 \mathrm{~m}$, 宽约 $500 \mathrm{~m}$, 平均厚度约为 $8 \mathrm{~m}$, 其总规模约为 $800 \times 10^{4} \mathrm{~m}^{3}$ 。由于松散堆积 土体一侧临沟, 在沟道径流的冲刷作用下产生 连续垮塌, 源源不断为泥石流提供物源, 使其 规模和流量得以增大。

\section{3 地形地貌}

根据调查, 黄葛沟泥石流流域在平面上呈 扇状, 中上游宽、下游窄, 这种上游开阔的地 
Risk Analysis and Crisis Response in Big Data Era (RAC-16)

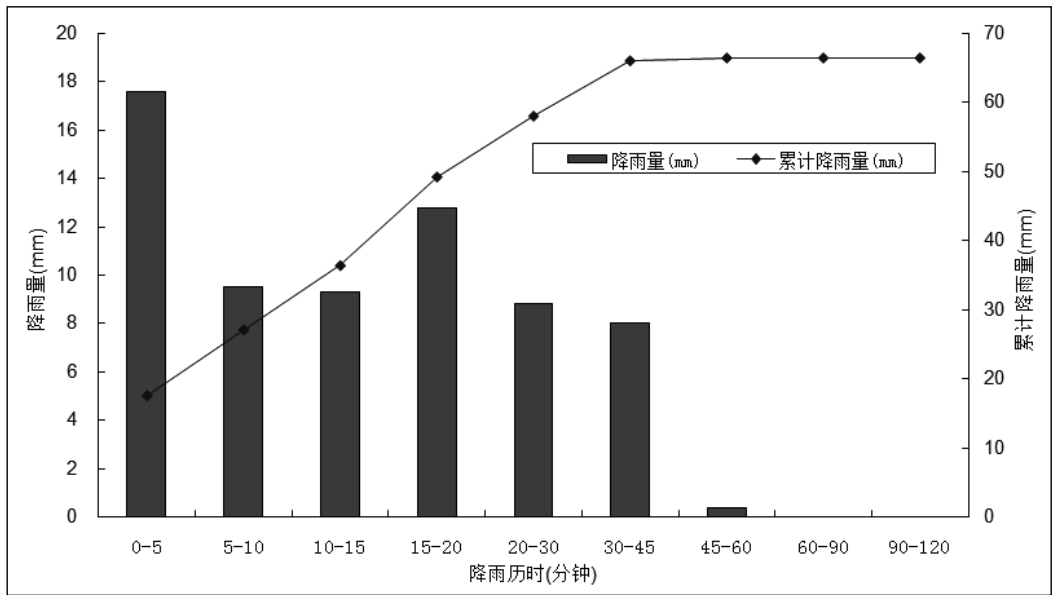

图 3, 田坝子沟泥石流小时降雨量放大后的分布特征

形在强降雨作用下极易迅速在上游形成大规 模的地表径流及沟道洪水, 为泥石流的发生提 供必要的水动力条件。调查发现, 田坝子沟流 域上游多见基岩出露, 地表水在段时间内通过 土壤下渗的能力有限, 这也在很大程度上加快 了地表径流和沟道洪水的快速形成。根据泥石 流发生过程中 $66.4 \mathrm{~mm}$ 的降雨量估算, 整个流 域在一个小时内汇集了约 $10 \times 10^{4} \mathrm{~m}^{3}$ 的地表径 流并形成洪水冲出, 并沿途启动松散土体而形 成泥石流。

\section{4. 低频泥石流的防灾减灾思考}

由于暴发周期较长, 低频泥石流在发生后, 经过若干年的自然演变, 沟口的许多证据都被 生长的植被所掩盖, 以至于人们难以对这些区 域存在的潜在危险进行有效识别, 这也是目前 低频泥石流防灾减灾中存在的共性问题。虽然 在早期我们的认识水平条件有限, 但随着对低 频泥石流研究的不断深入, 对其进行早期识别 并提前做出防灾减灾规划将会得以实现。

\section{1 田坝子沟泥石流潜在风险分析}

通过对 1997 年田坝子沟泥石流发生后的 调查发现，田坝子沟流域的扇状水系极为明显， 且沟口的老堆积扇及侵蚀深度也极为显著 (图 1)。这些宏观的形态特征其实都暗示着这里曾 经发生过大规模泥石流。同时，根据对该流域 的调查发现, 在重力及地表侵蚀作用下, 穆家 寨以上的沟床内已有较厚的松散土体堆积, 在
洪水作用下可成为泥石流物源的松散土体已 有相当的规模。尤其是在穆家寨沿沟的临空一 侧, 表层土体在重力作用下以崩塌形式进入沟 道的现象极为常见，也极易在沟道侧蚀作用下 启动形成泥石流。同时, 通过对田坝子沟泥石 流物源区和堆积区土体的粒度试验结果可以 看出, 在粒径小于 $2 \mathrm{~mm}$ 的所有土体中, 物源区 粒径小于 $0.1 \mathrm{~mm}$ 的土体累计百分含量约占总 数的 $90 \%$ 以上, 表明田坝子沟泥石流物源分布 粒径较为集中, 且多以细颗粒为主, 即物源启 动所需的临界水力学参数值较低。基于对流域 内松散土体的储量及粒径特征分析, 在暴雨情 况下，田坝子沟具有再次发生类似 1997 年规 模泥石流的可能性，地方政府部门应积极采取 应对措施, 确保沟口学校的安全。

\section{2 低频泥石流的监测预警问题}

通过分析 1997 年田坝子沟泥石流发生时 的降雨数据不难看出, 52 分钟内的 $66.4 \mathrm{~mm}$

(17.6 mm/5min) 短时强降雨是该次泥石流发 生的最主要诱因。通过对我国 22 次已发生的 典型低频泥石流降雨过程的统计发现, 虽然诱 发低频泥石流的降雨类型主要有短时强降雨、 持续降雨及短时强降雨+持续降雨三种类型, 但短时强降雨却是诱发低频泥石流的主导降 雨模式, 且低频泥石流的发生与小时降雨量之 间存在着显著的对应关系（图 5)。同时，统 计结果还表明, 小时降雨量为 $30 \mathrm{~mm}$ 与低频泥 石流的发生有极为显著的对应关系，可为田坝 
Risk Analysis and Crisis Response in Big Data Era (RAC-16)

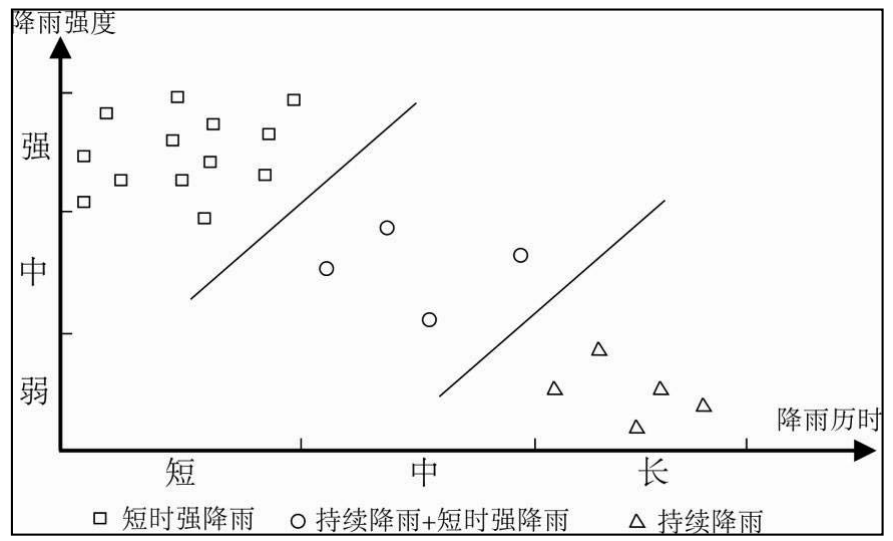

图 5, 诱发西南山区低频泥石流的降雨类型分区特征

子沟及其它地区的低频泥石流预警预报提供 参考。

\section{3 低频泥石流潜在风险的合理评估问题}

在早期的山区基础设施及城镇建设过程

中，因低频泥石流暴发周期长而存在的 “隐蔽 性”而对其危害程度的估计不足往往是造成灾 害的一个主要原因。由于对这类暴发周期较长 的泥石流孕灾规律认识不够深入, 对其造成的 灾害过程也往往被看作是随机的。但事实上, 很多这类灾害是可以有效避免的。通过对 1997 年田坝子沟泥石流成灾过程的调查发现, 该次 泥石流发生时, 沟口 213 国道的桥涵由于过流 断面较小而堵塞河道, 导致泥石流从沟道左岸 侧翻越沟道冲入学校及居民区, 是直接导致该 次泥石流成灾严重的最主要原因。这种现象在 很多早期的公路建设中极为常见, 由于对泥石 流规模的估计不足, 很多桥涵断面均按照洪水 的过流量进行设计, 难以满足泥石流流量对断 面的需求。随着对低频泥石流孕灾机制的不断 认识及政府部门的防灾减灾投入, 在工程及城 镇规划建设前通过科学合理的评价将会有效 降低灾害造成的风险。同样, 在一些已建在泥 石流潜在危险区的工程或城镇, 通过对低频泥 石流开展工程防治或监测预警, 也能将其造成 的灾害损失降到最低。

\section{参考文献}

[1]韦方强,谢洪,Jose L.Lopez 等.委内瑞拉 1999
年特大泥石流灾害.山地学报, 2000, 18(6): 580-582.

[2]胡凯衡,崔鹏,马超,等.宁南县矮子沟 “ 6.28 ” 特大灾害性泥石流成因和特征. 山地学 报,2012,30(6):696-700.

[3] Anping Pan. A Study on Residents' Risk Perception in Abrupt Geological Hazard. Journal of Risk Analysis and Crisis Response, 2, (1), 2012: 44-55.

[4]余斌,杨永红,苏永超等.甘肃省舟曲 8.7 特大 泥石流调查研究.工程地质学报, 2010,18(4):437-444.

[5]唐 川,章书成. 水力类泥石流起动机理与预 报研究进展与方向.地球科学进展, 2008, 23(8):787-793.

[6]韩林,余斌,鲁科.泥石流暴发频率与其形成 区块石粒径的关系.长江流域资源与环境, 2011, 20(9):1149-1156.

[7]倪化勇,吕学军,刘宇杰等.低频泥石流特征 及其预测初步探讨.工程地质学报，2007, 15(5):612-620.

[8]宗德孝,高必春. 1997 年 5 月云南昭通两次 大型泥石流灾害及防御对策. 灾害学, 1998,1 3(2):67-70.

[9]铁永波,周洪福,倪化勇.西南山区短时强降 雨诱发型低频泥石流成因机制分析一以四 川省宝兴县冷木沟泥石流为例. 灾害学, 2013, 28(3):110-113. 